structured support, supervision and training to junior doctors.

This project has highlighted the value of a local questionnaire in seeking anonymised, honest feedback from junior doctors and encouraging engagement in the QI process. We anticipate that the frequent turnover of junior doctors in the department will pose a challenge for the project. It is therefore being linked to formal quality improvement training and a local peer support hub to ensure sustainability. Low levels of trainee satisfaction are likely to be multifactorial in nature and can be effectively investigated with a structured online questionnaire. By identifying key areas of concern at a local level, targeted QI projects can be designed and led by trainees, with an overall improvement in satisfaction, working hours and training opportunities.

\section{AN ADVICE LEAFLET TO HELP JUNIOR DOCTORS IN ED MANAGE SHIFT-WORK ASSOCIATED FATIGUE}

'Louis Fiander, ${ }^{2}$ Laura Cottey. 'Intercalating Medical Student, University of Plymouth Peninsula School of Medicine and Dentistry (UK); ${ }^{2}$ ED Academic Clinical Fellow, University Hospitals Plymouth NHS Trust (UK)

\subsection{6/leader-2019-FMLM.50}

Background There are many physical, mental and social complications of fatigue associated with working shifts. Emergency Medicine is experiencing a crisis within the UK with a low recruitment rate and a high attrition rate. 24-hour Emergency Department (ED) provision requires doctors to work long, often unsociable shift patterns, at risk of becoming unsustainable. Junior doctors are vulnerable to this, and thus to suffering the aforementioned complications of fatigue. This further contributes to attrition, perpetuating the workforce problem.

Objectives

- Increased awareness amongst junior doctors and other important stakeholders of the effects of shift-work related fatigue.

- Junior doctors to be enabled to better manage fatigue associated with shift-work through sleep hygiene.

Methods Work was conducted within the ED at Derriford Hospital, University Hospitals Plymouth NHS Trust. Local wellbeing research was reviewed, establishing that ED staff had a high 'need-for-recovery' score compared to respondents in the validation study working jobs classed as 'stressful'. National Emergency Medicine Trainee Association surveys of 2015 and 2017 highlight key concerns for trainees as fatigue, workload and rota scheduling. These findings were contextualised through consultation with the Junior Doctors Representative Committee and ED Wellbeing Committee.

A printed advice leaflet was created, containing basic sleep science, highlighting potential complications of shift-work, and giving advice on how to manage shift-work associated fatigue. The leaflet was peer-reviewed, then disseminated to ED junior doctors.

Impact From feedback received, this leaflet has raised awareness of shift-work related fatigue. Recipients are better equipped to manage fatigue whilst working shifts and have tools to practice sleep hygiene.

Further measurement of improvement will involve an anonymised questionnaire and analysis of the Junior Doctor component of the imminent ED staff survey.

\section{AN OBSERVATIONAL STUDY EVALUATING THE IMPROVEMENT IN PERFORMANCE OF INPATIENT GASTROENTEROLOGY SERVICES FOLLOWING THE IMPLEMENTATION OF A TRANSFORMATION PLAN}

${ }^{1}$ Suraj Pathak*, ${ }^{2}$ Ajay Verma. ${ }^{1}$ Department of Cardiovascular Sciences and National Institute for Health Research Leicester Biomedical Research Unit in Cardiovascular Medicine, University of Leicester, Glenfield Hospital, UK; ${ }^{2}$ Kettering General Hospital NHS FT, Kettering, UK

\subsection{6/leader-2019-FMLM.51}

Introduction The incumbent arrangements were on Deene $\mathrm{C}$ Ward (DCW), 29 patients under the care of three Consultants doing twice weekly ward rounds (WR) not prospectively covered, newly admitted and unwell patients reviewed by any WR as a safety net arrangement.

This was transformed to a Digestive Diseases Unit (DDU), bed base reduced from 29 beds ( 3 side rooms, 3 × 6 bedded bays, a 5 bedded bay, \& a 3 bedded bay), to 20 beds, by reducing 6 bedded bays to 4 beds, and converting the 3 bedded bay to a nurse-led Gastroenterology Treatment Area (GTA) for day-case ambulatory patients. This facilitated the introduction of a Consultant of the Week (CotW) model.

The CotW, for 2 weeks (prospectively covered), is responsible for daily DDU WRs of all 20 patients under their care, review of in-patient (IP) referrals, in-reach into urgent care wards, and support of GTA. There is minimal outpatient (OP) commitment. Outcomes were analysed at 12 months to assess the impact on patient care.

Methods A retrospective observational study was conducted to benchmark and evaluate changes in consultant led care. Statistical analysis was performed using Microsoft Excel.

Conclusion The reconfiguration of Gastroenterology IP services has been a great success. A reduction in bed base (which many at management level were reticent about) has facilitated a CotW model of care to be implemented. The IP service is now SAFER compliant. Length of stay has significantly reduced by $26.2 \%$. Weekly discharges per bed, and Consultant reviews, has significantly increased by $34.2 \% \& 84.1 \%$ respectively. In addition, GTA treats $>90$ patients per month, generating income, preventing admissions, facilitating earlier discharges, and freeing capacity in the main hospital ambulatory unit. This reconfiguration shows that a CotW model of care is optimal, successful, and SAFER compliant, even if a bed base reduction is required to facilitate this.

\section{ARTIFICIAL INTELLIGENCE FOR HUMANITARIAN ACTION: AN INTERDISCIPLINARY APPROACH TO COMMUNICABLE DISEASES IN REFUGEES}

${ }^{1,2} \mathrm{R}$ Jarral ${ }^{*},{ }^{3} \mathrm{~T}$ Kells, ${ }^{4} \mathrm{~N}$ Yue Lin, ${ }^{5} \mathrm{~A}$ Mason-Mackay, ${ }^{6} \mathrm{~K}$ Sharma. ${ }^{1} \mathrm{NHS}$ UK; ${ }^{2}$ Tech Futures Lab, New Zealand; ${ }^{3}$ Aderant, New Zealand; ${ }^{4}$ University of Auckland, New Zealand; ${ }^{5}$ Crunch and Flourish, New Zealand; ${ }^{6}$ Mission Ready HQ, New Zealand

\subsection{6/leader-2019-FMLM.52}

The 'Ora' platform was developed along-side clinicians in a collaborative effort, winning the Microsoft 'Artificial Intelligence (AI) for Good' challenge with an AI powered tool for humanitarian crises. Geographically-tagged social media sentiment analysis is proposed as an increasingly validated metric for rapidly modelling disease incidence - supported by 